\title{
Seramik Malzemelerde Piroplastik Deformasyonların Deneysel Analizi ve Sonlu-Elemanlar Yöntemiyle Doğrulanması
}

\section{Experimental Analysis and Finite-Element Verification of Pyroplastic Deformations in Ceramic Materials}

\author{
Aybike Ürkmez ${ }^{1}$,, Sefa Manav ${ }^{1}{ }^{\circledR}$, Naci Zafer ${ }^{2 *}$ \\ ${ }^{1}$ Eczacıbașı Yapı Gereçleri A.Ş, Bilecik, TÜRKiYE \\ ${ }^{2}$ Eskişehir Osmangazi Üniversitesi, Makine Mühendisliği Bölümü, Eskişehir, TÜRKiYE \\ Sorumlu Yazar / Corresponding Author*: nzafer@ogu.edu.tr
}

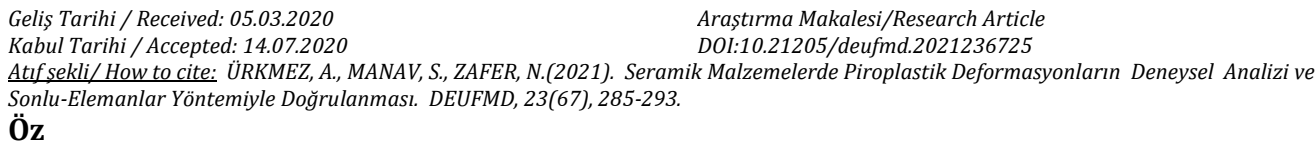

Seramik sağlık-gereçleri ısıl işlem sırasında sıvı faz sinterlemesi ile mukavemet kazanırken kalıcı piroplastik deformasyon da geçirirler. Bu nedenle, döküm yapılarak elde edilecek olan yarı mamul formunun pişirim sırasında oluşan piroplastik şekil değiştirmeler dikkate alınarak tasarlanması gerekir. Bu sayede, istenilen nihai ürün formu hassas olarak tam da pişirim sonrasında elde edilmiş olur. Yarı mamul ürün kalıp formları genellikle tecrübeye dayalı olarak ve benzer ürün prosesleri takip edilerek tasarlanmaktadır. Bu çalıșmada, iki farklı lavabonun piroplastik deformasyon analizi hem deneysel hem de Sonlu Elemanlar Metodu (SEM) kullanılarak gerçekleștirilmiştir. İlk olarak basit şekilli bir çubuğun farklı mesnet aralıklarında deneysel deformasyonu incelenmiştir. Çalışmanın devamında, bu çubukların aynı mesnet mesafelerinde ANSYS ortamında Sonlu Elemanlar Analiz (SEA) çalıșmaları yapılmış ve deformasyon değerleri doğrulanmıştır. Nümerik yaklaşımın geçerliliği gösterildikten sonra, geçmişte deneme yanılma yöntemi ile geliştirilmiş kalıplarda üretilmekte olan iki farklı lavaboya ait 3-boyutlu modeller oluşturulmuş, sonlu elemanlar metoduyla bu modeller üzerinde gerçekleştirilen piroplastik deformasyon analiz sonuçları sunulmuştur.

Anahtar Kelimeler: Seramik sağlık gereçleri, piroplastik deformasyon, sonlu elemanlar analizi, tasarım

\section{Abstract}

Ceramic sanitarywares permanently undergo pyroplastic deformations, while gaining strength by liquid phase sintering during heat treatment. Therefore, green product forms are designed in consideration of the pyroplastic distortions formed during firing. In this way, target form of the product is obtained with a high degree of accuracy right after firing. Green product mould forms are usually designed with experience and by following similar product processes. In this study, pyroplastic deformation analyses of two washbasin products are carried out both experimentally and numerically by the Finite Element Method (FEM). First, experimental deformation of simple shaped bars in different support distances are investigated. Next in the study, analysis and verification of the bar deformations are performed using the same support distances by application of the finite element method in the ANSYS environment. Following the demonstration of the validity of numerical approach, 3-dimensional models of two washbasin products are created from molds made in the past by the traditional trial-and-error approach, and the results of the finite element based pyroplastic deformation analyses are presented.

Keywords: Ceramic sanitaryware, pyroplastic deformation, finite element analysis, design 


\section{Giriş}

Seramik sağlık gereçleri, seramikten yapılmış [12], banyo ve mutfaklarda kullanılan mutfak, banyo, tuvalet gibi yaşam alanlarında kullanılan lavabo, klozet, bide, pisuar ve duş tekneleri lavabo, klozet ve pisuar vb. ürünleri kapsar. Seramik sağlık gereç bünyeleri (yapıları) vitrifiye (VC) ve fine fire clay (FFC) olmak üzere iki standart çamur reçetesinden oluşurlar. FFC bünye reçetesini $\mathrm{VC}^{\prime}$ den ayıran temel hammadde kalsine edilmiş kaolen kullanımıdır [3]. Farklı hammaddeler kullanılabilmesine rağmen VC ve FFC ürün proses aşamaları (tasarım, kalıp hazırlama, çamur hazırlama, sır hazırlama, şekillendirme, kurutma, sırlama, pișirme, kalite ayırım, paketleme ve servis) aynıdır [4]. Genel olarak kil, kaolen, feldspat ve kuvars türü inorganik hammaddelerden hazırlanarak sırlanan ve $1200-1250^{\circ} \mathrm{C}, 10-15$ saat civarında pişirim sonucu camlaşmıș (șeffaf veya renkli) bir sır örtüsü ile kaplanan bu ürünlere "Vitrifiye Seramik" adı verilir [5-6].

Isıl işlem sırasında seramiklerde sıvı faz sinterlemesi görülür [7-8]. Sinterleme sırasında bünye poroziteleri küçülür, boyutsal değişiklikler gerçekleşir, mukavemet artar. Sinterleme sırasında oluşan viskoz akış piroplastik deformasyona sebep olur [9]. Piroplastik deformasyon, pişirim sırasında seramik bünyenin bükülmesinin ölçülmesi ile gösterilebilir [10-11]. Pișirim sonrası ürün kalıcı şekil değişikliğine uğradığı için ürün dökümü yapılan kalıbın tasarımında, pișirim sırasında üründe oluşacak şekil değişikliğinin göz önüne alınması gerekir. Kalıp tasarımı, bu nedenle, tecrübeye dayalı yapılır ve ilk seferde kabul edilebilir bir kalıp yapmak zordur. Ürün devreye alım sürecinde kalıplara çok defa tadilat yapılarak zaman ve iş gücü harcanır.

$\mathrm{Bu}$ çalıșmada, seramik sağlık gereçlerinin imalatında kullanılan kalıplarda oluşan piroplastik șekil değișikliklerinin Sonlu Elemanlar Analizi (SEA) ile öngörülebilir olduğu gösterilmiş, bilgisayar ortamında simülasyonla elde edilen bu bilginin uygun kalıp tasarımı geliştirmede kullanılmasıyla da iş gücü ve zaman kaybından tasarruf edilebileceği ortaya konmuștur. Literatürde, sınırlı sayıda da olsa, benzer kurguya sahip, yerçekimi etkisi altında sinterleme sonrası oluşan piroplastik deformasyonların incelendiği, çalışmalar bulunmaktadır [12-14]. $\mathrm{Bu}$ ve benzer çalışmaların farklı ürün ve kalıp tasarımlarına genelleştirilerek uygulanabilir olduğu anlașılmaktadır.

Her ne kadar, sonlu elemanlar analizinin mühendislik sistemlerinin gerçek çalıșma şartlarında (farklı kuvvet, ISı, titreşim vb etkiler altında) nasıl cevap vereceklerinin tahmin edilmesinde kullanılması 100 yılı aşkın süredir yapılıyor olsa da [15], seramik sağlık gereçlerinde olduğu gibi, henüz pek çok alana yeterince uygulanmamıștır. Bunun önemli bir nedeni, sonlu elemanlar modellerinin 3B uzayda binlerce eleman içermesi, elemanlar arası etkileşimlere ait kısmi diferansiyel denklemlerin tümünün birlikte çözülmesinin çok fazla sayıda nümerik işlem gerektirmesi, bu ihtiyacın da 1950'lerden sonra karșılanmaya bașlaması, etkin-hızlı hesaplamaların ve model doğrulamalarının ise 1980 'lerden sonra artan bir ivmeyle (farklı pek çok yazılım sayesinde) mümkün olmasının sağlanmıș olmasıdır.

\section{Materyal ve Metot}

$\mathrm{Bu}$ çalışmada, seramik sağlık-gereçlerinde sinterleme sonrası oluşan şekil değișimlerinin deneysel karakterizasyonu ve SEA analizi gerçekleştirilmiştir. Bu amaca yönelik olarak, öncelikle, döküm yöntemi ile şekillendirilen seramik test çubuklarının farklı mesnet mesafelerinde pişirim sırasındaki deformasyonları deneysel olarak incelenmiștir. Takiben, elde edilen deneysel bulgularla, Sonlu Elemanlar Modeli (SEM) oluşturulan bu test çubuğu için SEA gerçekleștirilmiş ve deneylerde elde edilen sonuçların makul yakınlıkta nümerik simülasyonla tahmini sağlanmıştır. Çalışmanın son așamasında, seri-üretimi devam eden örnek 2 adet lavabo için piroplastik deformasyonların SEA ile tespiti yapılmış, geleneksel olarak deneme-yanılma yoluyla geliştirilen kalıp tasarımlarında iyileştirme yapılması mümkün hale getirilmiştir.

SAE analiz ile hem deformasyon hem de stres dağılımları elde edilmiştir. Buna rağmen, çalışma boyunca, seramik sağlık gereçleri için daha kritik olduğu için, çoğunlukla deformasyon analizi sonuçları üzerinde durulmuştur. Bu nedenledir ki, gerilme değerlerinin deneysel tespiti yapılmamıştır. 


\section{Bulgular}

\subsection{Deneysel Analiz}

Seramik sağlık gereçlerinde pişirim sonrası oluşan deformasyonların belirlenmesi için Eczacıbaşı Yapı Gereçleri AŞ'de üretimde kullanılan FFC çamuru kullanılarak alçı kalıplarda boyutları $244 \times 22 \times 11.7 \mathrm{~mm}$ olan 4 adet test çubuğu hazırlanmıştır. Daha sonra, bu çubuklar $20,15,10$ ve $5 \mathrm{~cm}$ olmak üzere 4 farklı mesnet mesafesinde refrakter malzemelerle desteklenmiş (Şekil 1), $1200^{\circ} \mathrm{C}^{\prime}$ de 13 saat pişirilmiştir. Pişirme sırasında, azalan mesnet mesafeleri için çubukların desteksiz bölgeleri azaldığından, sinterleme sırasında oluşan sıvı fazın ve yerçekimi kuvvetinin etkisi ile çubukların deformasyon miktarlarının değiștiği gözlenmiştir. Pişirim sonrası (Şekil 2), numunelerin ortaları ve uç kısımları arasındaki yükseklik farkları ölçülerek, deformasyon miktarları milimetre cinsinden belirlenmiştir.

Yapılan ölçümlerle, $20 \mathrm{~cm}$ mesnet mesafede deformasyon $8.3 \mathrm{~mm}, 15 \mathrm{~cm}$ 'de $4 \mathrm{~mm}, 10 \mathrm{~cm}$ 'de $1 \mathrm{~mm}, 5 \mathrm{~cm}$ 'de $0.1 \mathrm{~mm}$ gerçekleşmiştir. Mesnet mesafesi azaldıkça deformasyon değerinin azalması, yerçekimi etkisi ile desteksiz kalan bölgenin ağırlığı ile sinterleme sırasında oluşan gerilmenin artmasının bir sonucudur.

\subsection{SEA}

Bu aşamada, seramik sağlık-gereçlerinde pişirim deformasyonlarının sonlu elamanlar yöntemine dayalı analiz çalışmalarıyla doğrulanması hedeflenmiştir. Bunun için, ANSYS programında refrakter bloklar üzerine oturan bir test çubuğu modeli oluşturulmuş (Şekil 3), takiben analiz için çubuk $5 \mathrm{~mm}$ ağlara bölünerek yaklaşık 1.5 milyon adet mesh içeren SEM hazırlanmıștır. Çubuk ve yüzey temas bölgelerinde pürüzlülük (roughness) değeri $0.65 \mathrm{~mm}$, Poisson değeri 0.3 olarak alınmış, çamur elastisite modülü için deneysel sonuçlara ulaşılmasını sağlayacak uygun bir değerin aranmasına çalışılmıştır. $\mathrm{Bu}$ amaçla, deneysel olarak $20 \mathrm{~cm}$ mesnet mesafesinde elde edilen deformasyon değerine SEA ile $6 \times 10^{6} \mathrm{~N} / \mathrm{m}^{2}$ elastik modülü değeri için \% 95 yakınlıkta ulaşıldığı belirlenmiş ve bu değer çalışma genelinde kullanılmıștır.

Seramik çamuru elastisite modülünün 0.5-3 MPa civarında olduğu ve sıcaklıkla daha da arttığı [16], Poisson oranının da 0.2-0.5 arasında olduğu, yoğunlukla arttığı bilinmektedir [14]. Ayrıca, toprak için elastisite modülünün 1-30 Ma ve Poisson değerinin 0.1-0.4 olması, SEA için varsayılan bu değerlerin makul olduğuna işaret etmektedir.

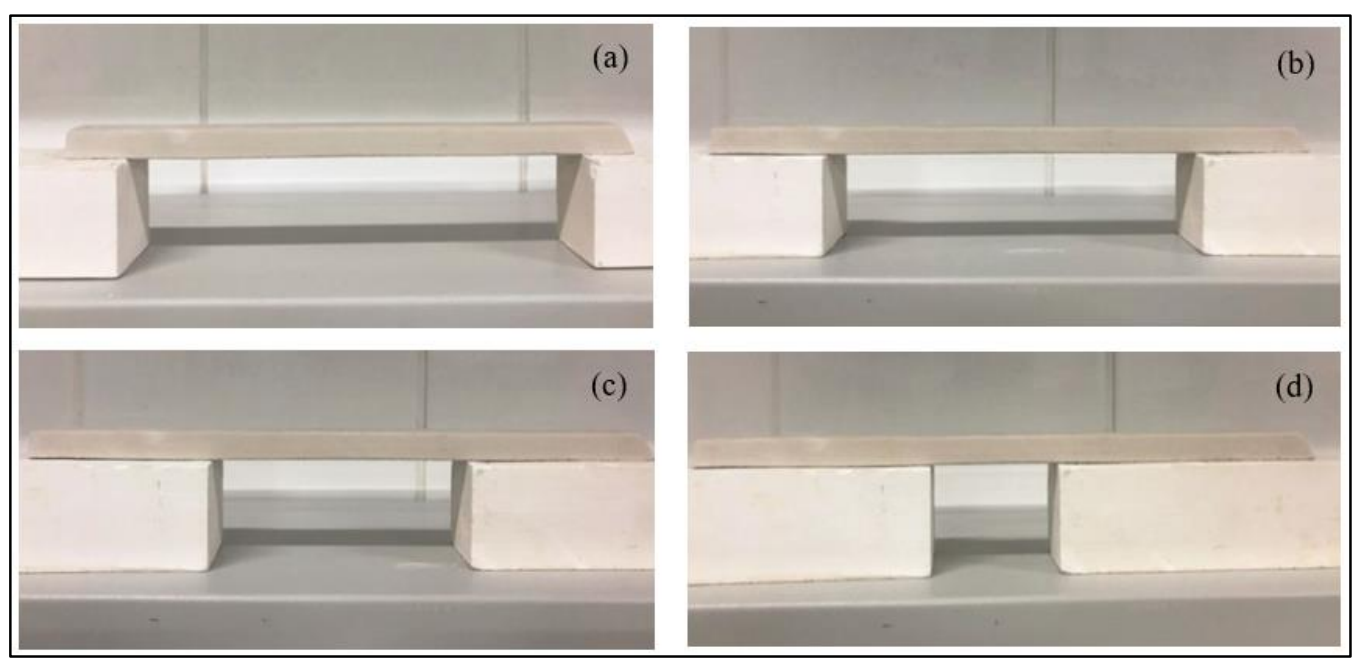

Şekil 1. Deformasyon çubuklarının mesnet mesafeleri; a) $20 \mathrm{~cm}$, b) $15 \mathrm{~cm}$, c) $10 \mathrm{~cm}$, d) $5 \mathrm{~cm}$ 


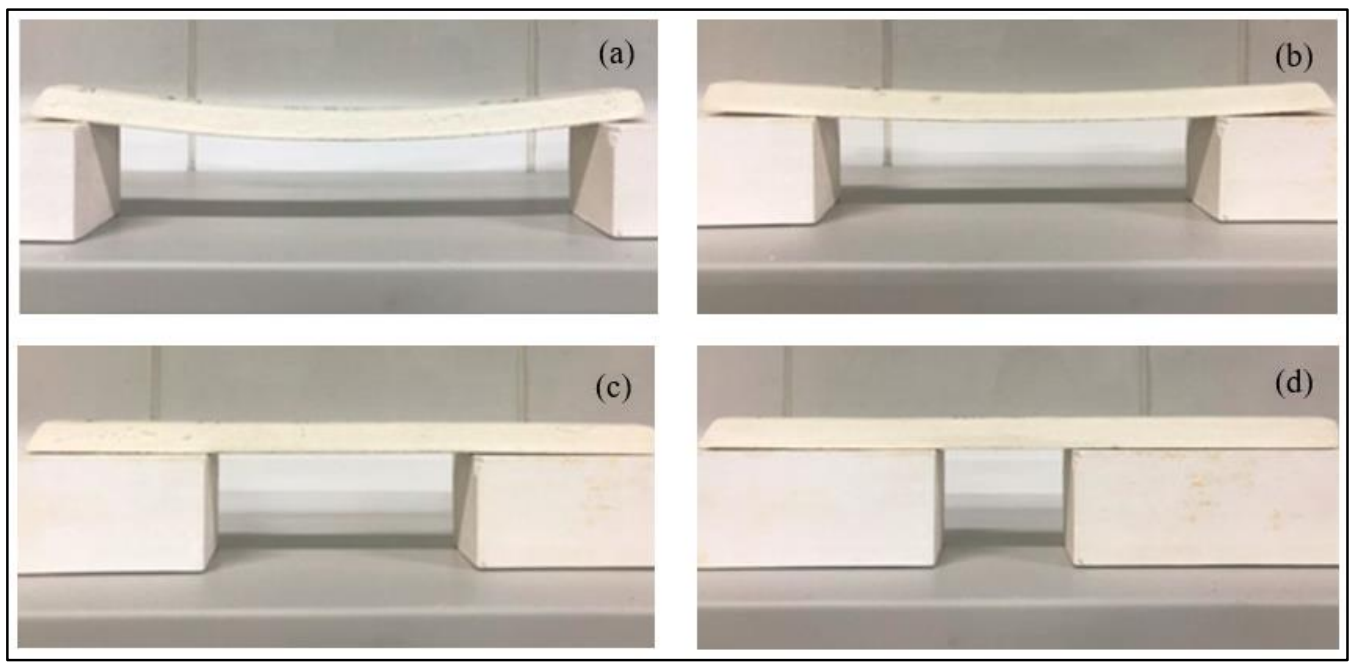

Şekil 2. Pişirim sonrası çubukların deformasyon görüntüleri; a) $20 \mathrm{~cm}$, b) $15 \mathrm{~cm}$, c) $10 \mathrm{~cm}$, d) $5 \mathrm{~cm}$

$\mathrm{Bu}$ çalışmada, ANSYS SEA analizleriyle hesaplanan stres (gerilme) ve deformasyon (gerinim) dağılımları renk haritalarıyla (3B verilerin 2B'de anlaşılmasına hizmet etmek üzere) sunulmuştur. Bu renk haritalarında artan değerlerle renklerin maviden yeșile ve en son (en kritik bölgeleri gösteren) koyu kırmızıya doğru dönüșmektedir.

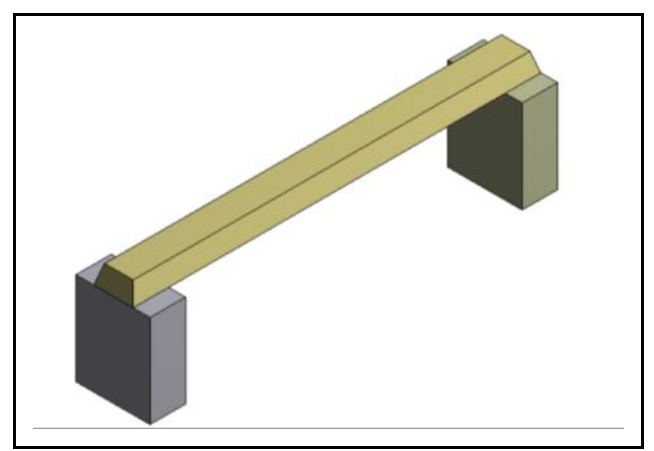

Şekil 3. SEM analiz için hazırlanmış $20 \mathrm{~cm}$ mesnet mesafeli çubuk

Şekil 4.a'da görüleceği üzere $20 \mathrm{~cm}$ mesnet mesafesi durumunda azami deformasyon değeri ANSYS analiziyle $7.964 \mathrm{~mm}$ olarak hesaplanmıştır. Gerilmenin çubuğun desteklerin tam olarak bittiği yerde maksimum $0.0357 \mathrm{Mpa}$ değerine ulaştığı azami deformasyon bölgesindeyse yaklaşık 0.19 MPa olduğu da aynı şekilde görülmektedir. $15 \mathrm{~cm}$ mesnet mesafesinde azami deformasyon $3.99 \mathrm{~mm}$ 'dir (Şekil 4.b). Deneysel deformasyon sonucu bu mesnet mesafesi için $4 \mathrm{~mm}$ ölçülmüştü. Aradaki fark kabul edilebilir düzeydedir. Deneysel pişirim deformasyonlarında da görüldüğü gibi mesnet mesafesi azaldığında SEA değerlerinde de düşüş görülmüștür. $20 \mathrm{~cm}$ mesnet aralığına göre neredeyse yarı yarıya bir düşüş olmuştur. Şekil 4.b'de ayrıca $15 \mathrm{~cm}$ mesnet mesafesinde oluşan gerilimler de verilmiştir. Gerilim en fazla yine mesnetin çubuğa temasın bittiği çizgide olmuştur. Gerilim $20 \mathrm{~cm}$ mesnet aralığında oluşandan daha düşüktür. Bunun sebebi aradaki mesafenin azalması ile çubuğun daha az değişim geçirmesidir. Mesnetler arası mesafe $10 \mathrm{~cm}$ olduğunda deformasyon 1.1 mm'ye düşmektedir (Şekil 4.c). Deneysel deformasyon analizi ile değerler paralel gözükmektedir. Yine aynı şekilde, mesnetler arası mesafe $10 \mathrm{~cm}$ olduğunda gerilim değerlerinde de deformasyon analizinde olduğu gibi düşüş görülmektedir. Son olarak mesnet mesafe aralığ $5 \mathrm{~cm}$ olarak çalıșılmıștır. $\mathrm{Bu}$ aralıkta deformasyon yok denecek kadar düşüktür (Şekil 4.d). Mesnetler arası mesafe 5 $\mathrm{cm}$ olduğunda (deformasyonun yok düzeyinde olmasına da bağlı olarak) gerilim değerinin de çok azaldığı Șekil 4.d'de görülmektedir. Deneysel yöntem ile analizde olduğu gibi SEM'de de mesnetler arası mesafe azaldıkça deformasyon azalmıştır. 


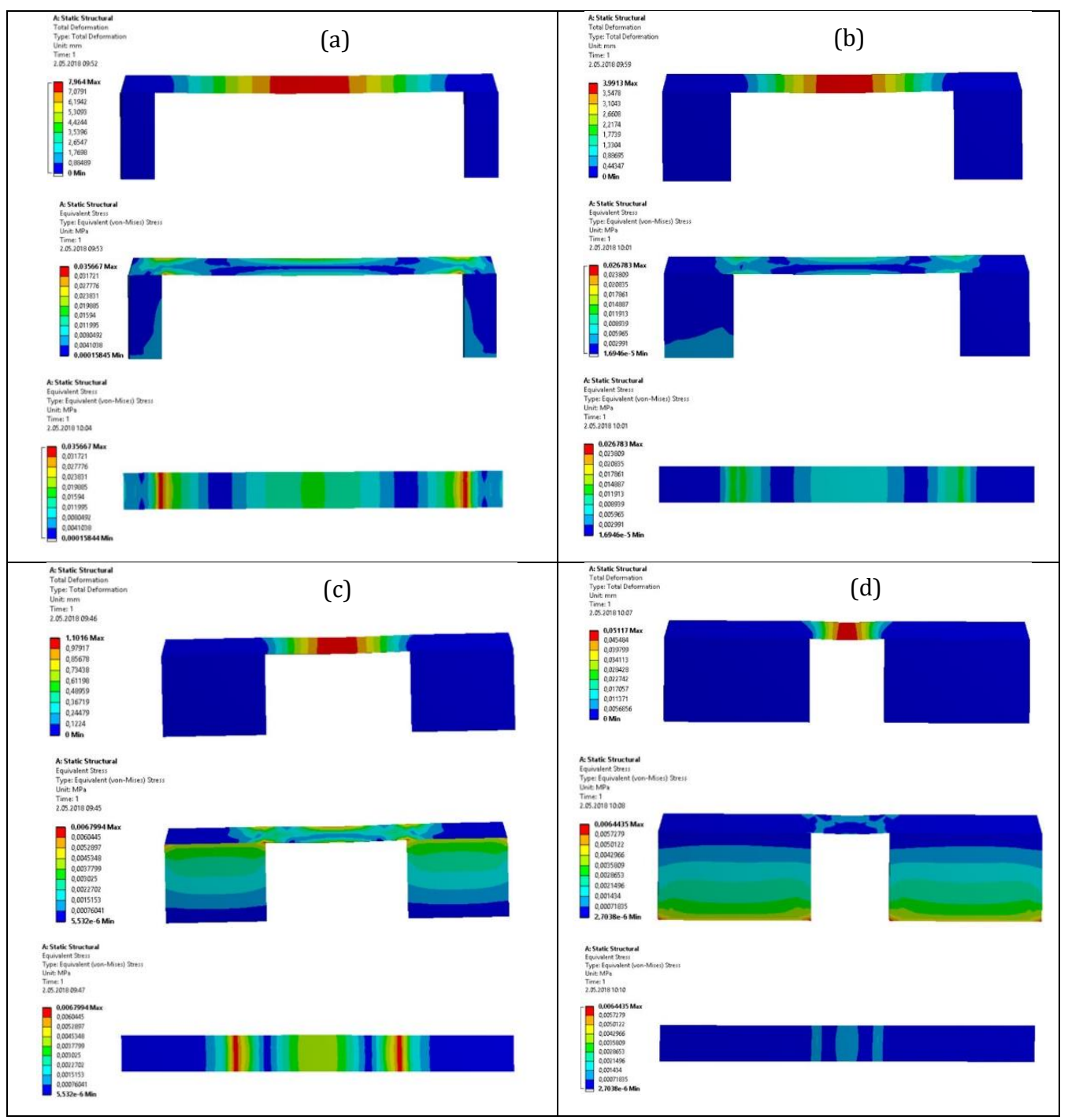

Şekil 4. Farklı mesnet mesafelerinde SEA deformasyon sonuçları

a) $20 \mathrm{~cm}$, b) $15 \mathrm{~cm}$, c) $10 \mathrm{~cm}$, d) $5 \mathrm{~cm}$

Tablo 1'den de anlaşlacağı üzere deneysel ve SEA deformasyon sonuçları birbirine oldukça yakındır. Bu durum, SEA çalışmalarının ürün kalıp tasarım çalışmalarına fayda sağlama potansiyeli olduğunu da göstermektedir. Nihai ürün ile bu ürünün dökümünün yapılacağı kalıplar pişirim sırasında oluşacak deformasyon sebebi ile farklılık gösterdiğinden, pișirim sonrası oluşacak deformasyonların SEA ile tahminlerinin yapılabilmesi kalıp tasarımına önemli bir fayda sağlayabilecektir.
Tablo 1. Deformasyon karşılaştırılması

\begin{tabular}{ccc}
$\begin{array}{c}\text { Mesnetler } \\
\text { arası mesafe } \\
(\mathrm{cm})\end{array}$ & $\begin{array}{c}\text { Deneysel } \\
\text { deformasyon } \\
(\mathrm{mm})\end{array}$ & $\begin{array}{c}\text { SEM analiz } \\
\text { deformasyonu } \\
(\mathrm{mm})\end{array}$ \\
\hline 20 & 8.3 & 7.96 \\
15 & 4 & 3.99 \\
10 & 1 & 1.10 \\
5 & 0.1 & 0.05 \\
\hline
\end{tabular}


DEÜ FMD 23(67), 285-293, 2021

\subsection{SEA ile ürün ve kalıp tasarımı:}

Seramik sağllk-gereçleri üretimde pișirim sırasında sinterlenerek mukavemet kazanır, bu sırada kalıcı şekil değişikliği geçirirler ve deformasyona uğrarlar. $\mathrm{Bu}$ nedenle, oluşan deformasyonlar ve şekil değişiklikleri göz önünde tutularak kalıp tasarım boyutları, pişirim sonrasında istenilen ürün boyutlarından farklı olarak tasarlanır. Nihai üründe istenilen boyutlara göre kalıp tasarımlarının yapılması geçmiş tecrübeyle ve/veya deneme-yanılma yoluyla yürütülen faaliyetlere dayanır.

Önceki bölümde ortaya konduğu üzere, deneysel ve SEA ile elde edilen deformasyon sonuçlarının birbirine oldukça yakındır. Bu sonuç, ürün kalıp tasarımlarının ilgili analiz çalışmalarından edinilen bilgiye dayalı olarak yapılabileceğini göstermektedir. Bu gerekçeyle, çalışmanın bu aşamasında, seçilen (Eczacıbaşı Yapı Gereçleri AŞ'de üretilen) görsel olarak aynı ancak boyutları farklı iki örnek ürüne ait SEM modellerinin öncelikle nihai (istenilen, bitmiş) boyutlarına göre yapılmasına karar verilmiş, ANSYS programı ile SEA sırasında yerçekimi ivmesinin ters (yukarı yönlü) uygulanmasıyla ters deformasyonlarla daha doğru kalıp boyutlarına ulașılması hedeflenmiştir. $\mathrm{Bu}$ planlamaya uygun olarak, ANSY'de deformasyon analizlerinin yapılması ve sonuçların deneme yanılma yöntemi ile geçmişte üretilmiş ve kullanımda olan kalıp boyutları ile karşılaştırılması hedeflenmiștir.

Eczacıbaşı Yapı Gereçleri A.Ş.'de farklı boyutlarda imalatı yapılmakta olan Şekil 5'deki ürün bu çalışmalar için seçilmiştir. Ürüne ait kritik boyutlar șekil üzerinde A-B-B1-B2 olarak gösterilmiștir. B1 ve B2 çubuk analizlerindeki mesnetler gibi düşünüldüğünde, yer çekimi kuvvetinden dolayı en fazla değişimin B'de olması gerektiği anlaşılmaktadır.

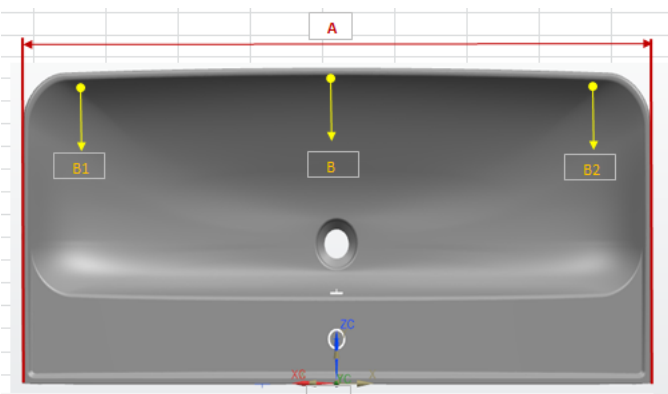

Șekil 5.63 cm ürün tasarımı
3.3.1. Örnek ürün-1 çalışması: Çalışma konusu ilk ürün Şekil 6'da, pişirim sonrası istenilen ürün, kalıp ve pişirim sonrası ürün boyutları Tablo 2'de görülmektedir. Kalıp B boyutu nihai ürün boyutundan $4 \mathrm{~mm}$ fazla olarak tasarlanmıștır. Pişirim sonrası ürün $\mathrm{B}$ boyutu istenilen değerden $2.5 \mathrm{~mm}$ fazla gelmiştir. Kalıp tasarımında B boyutunun $1.5 \mathrm{~mm}$ fazla hesaplandığ görülmüştür. Önceki bölümde öngörüldüğü gibi en fazla deformasyon B boyutunda olmuştur, B1 ve B3 boyutlarında değişiklik olmamıştır.

$63 \mathrm{~cm}$ ürün nihai boyutları SEM'de modellendikten sonra ürün batarya bölgesinden sabitlenmiştir. Yerçekimi kuvveti yukarı doğru uygulanarak deformasyon ters analiz edilmiş, oluşan deformasyon ile kalıp boyutları elde edilmiştir. Batarya bağlantı bölgesi (A) Şekil 7'de görüldüğü gibi neredeyse hiç deforme olmamıștır. En fazla deformasyon pişirilen ürün deformasyonu ile aynı yerde, ürün bant bölgesinde (B) olușmuștur. Ürün tasarım ve ürün istenilen boyutları ile SEA kalıp boyut sonuçları yine Tablo 2'de verilmiştir. Kalıp B boyutu pişirim sonrası $4 \mathrm{~mm}$ deformasyon olacağını ön görürken, SEA ile $2.7 \mathrm{~mm}$ ters deformasyon değeri vermiştir. $\mathrm{Bu}$ değer istenilen ürün boyutuna eklenerek kalıp boyutu elde edilmiștir. Görülmüştür ki, SEA ile mevcut kalıp boyutlarından daha yakın ve daha tutarlı değerler elde edilmiştir.

Şekil 8'de ürün stress analizi verilmiștir. En fazla stresin ürünün arka batarya bağlantı bölgesinde olacağl görülmüştür. Bunun sebebi pişirim sırasında ürün ve ürünün temas ettiği bölge arasındaki sürtünmedir. Oluşan deformasyon ile beraber ön bantta da gerilim oluşmuştur.

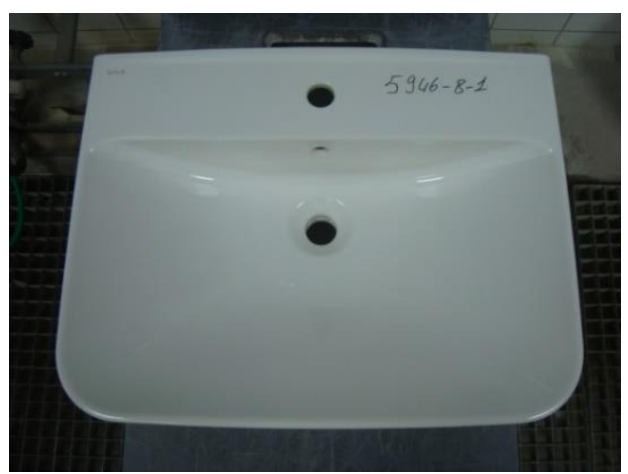

Șekil 6. 63 cm ürün 
DEÜ FMD 23(67), 285-293, 2021

Tablo $2.63 \mathrm{~cm}$ ürünle ilgili boyutlar $(\mathrm{mm})$

\begin{tabular}{lcccc}
\hline & A & B1 & B & B3 \\
\hline İstenen ürün & 630 & 485 & 485 & 485 \\
Kalıp & 630 & 485 & 489 & 485 \\
Pișirilmişürün & 630 & 485 & 487.5 & 485 \\
SEA ile kalıp & 630 & 486 & 487.7 & 486 \\
\hline
\end{tabular}

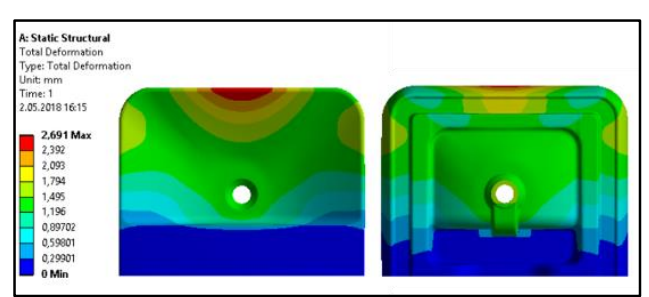

Şekil 7. $63 \mathrm{~cm}$ ürün deformasyon analizi

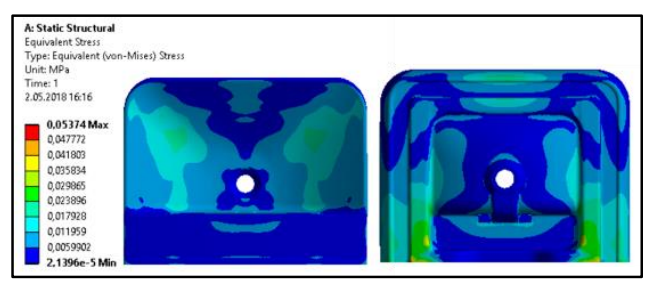

Şekil $8.63 \mathrm{~cm}$ ürün stress analizi

3.3.2. Örnek ürün-2 çalışması: $78 \mathrm{~cm}$ ürün Şekil 9'da, nihai ürün ve tasarım boyutları Tablo 3'de görülmektedir. Kalıp, pișirim sonrası A, B1 ve $B 3$ boyutlarında deformasyon olmayacağ öngörülerek nihai ürünle aynı boyutlarda, B boyutunda ise $5 \mathrm{~mm}$ deformasyon olacağ öngörülerek tasarlanmıştır. Pişirim sonrası A boyutu $1 \mathrm{~mm}$ B1 ve B3 boyutları $1.5 \mathrm{~mm}$ deforme olmuştur, halbuki $63 \mathrm{~cm}$ üründe $A, B 1$ ve B3 boyutlarında değişim görülmemişti. $\mathrm{Bu}$ farkın sebebi ürün boyutu arttığında ürün ağırlığının da artması ve pişirim sırasında viskoz fazın daha fazla etkilenmesi olabilir. $78 \mathrm{~cm}$ ürün $\mathrm{B}$ boyutunda $4 \mathrm{~mm}$ deformasyon olmuştur. Önceki bölümlerde görüldüğü gibi ürün boyutlarının artması ile beraber deformasyon miktarları da artmıştır.

$78 \mathrm{~cm}$ ürün nihai boyutları modellendikten sonra ürün batarya bölgesinden sabitlenmiştir. Yerçekimi kuvveti yukarı doğru uygulanarak deformasyon ters analiz edilmiş, kalıp boyutları elde edilmiştir. Batarya bağlantı bölgesi Şekil 10 'da görüldüğü gibi neredeyse hiç deforme olmamıştır. En fazla deformasyon pişirilen ürün deformasyonu ile aynı yerde, ürün bant bölgesinde oluşmuştur.
Ürün tasarım ve ürün istenilen boyutları ile SEA kalıp boyut sonuçları da yine Tablo 3'de verilmiştir. Ürün kalıp boyutu pişirim sonrası 5 $\mathrm{mm}$ deformasyon olacağını ön görürken gerçekte bu değer $4 \mathrm{~mm}$ olmuştur. SEA $3.3 \mathrm{~mm}$ deformasyon değeri vermiştir. Tasarım sırasında A, B1 ve B3 boyutlarında değişim olmayacağı düşünülmüş anca pişirim sonrası bu bölgelerde de deformasyon oluşmuştur. SEM analiz sonuçlarında ise B1 ve B3'te $2 \mathrm{~mm}$ deformasyon olacağı görülmüştür. Pişirim sonrası oluşan $1.5 \mathrm{~mm}$ deformasyona mevcut kalıptan daha yakın değer sağlamıștır. $78 \mathrm{~cm}$ ürün $63 \mathrm{~cm}$ ürün gibi arka bölgede sürtünmeden kaynaklı gerilimin yüksek olduğu görülmektedir (Şekil 11).

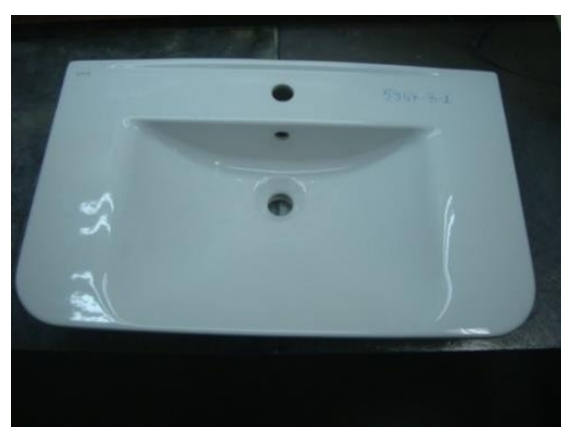

Şekil $9.78 \mathrm{~cm}$ ürün

Tablo $3.78 \mathrm{~cm}$ ürünle ilgili boyutlar (mm)

\begin{tabular}{lcccc}
\hline & $\mathrm{A}$ & $\mathrm{B} 1$ & $\mathrm{~B}$ & $\mathrm{~B} 3$ \\
\hline İstenen ürün & 780 & 485 & 485 & 485 \\
Kalıp & 780 & 485 & 490 & 485 \\
Pișmiş ürün & 779 & 483.5 & 486 & 483.5 \\
SEA ile kalıp & 780 & 487 & 488.3 & 487 \\
\hline
\end{tabular}

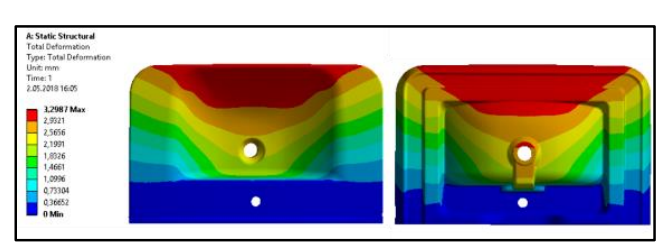

Şekil 10. $78 \mathrm{~cm}$ ürün deformasyon analizi

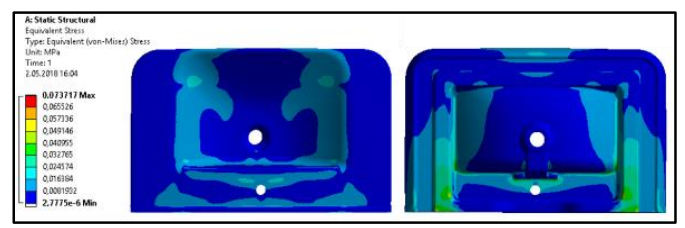

Şekil 11. $78 \mathrm{~cm}$ ürün stress analizi 


\section{Tartışma ve Sonuç}

Bu çalıșmada, seramik sağlık gereçlerinde piroplastik deformasyonun SEA ile doğrulanması çalışılmıștır. Seramik sağlık gereçlerinde yarı mamul pişirim sürecinde sinterlenerek mukavemet kazanır ve bu sırada kalıcı deformasyona uğrar. Pişirim sonrası istenilen ürün boyutları ve oluşacak deformasyon göz önünde tutularak ürün tasarımı yapılır. Günümüzde tasarımlar benzer ürünlerden yola çıkılarak yapılmaktadır. Yapılan tahminler ile her zaman doğru sonuçlar elde edilemediği için ürün devreye alım süreçleri uzamaktadır. Pişirim sonrası ürün boyutlarında istenilen değerlere ulaşılana kadar kalıp tasarımında tadilatlar yapılır, çok yoğun iş gücü ve zaman kaybina sebep olur.

Döküm yöntemi ile șekillendirilen test çubukları uçlarından farklı mesafelerde mesnetlerle desteklenerek pişirilmiștir. Dört farklı mesnet arası mesafe için dört test çubuğunun pişirimi gerçekleştirilmiş ve destekler arası mesafe arttıkça deformasyonun arttığı görülmüştür.

Çalışmanın devamında, SEA ile deneysel analiz sonuçlarının elde edilmesi üzerinde durulmuștur. Deneysel analizde kullanılan çubukların pişirim öncesi boyutları SEM'de modellenmiş ve aşağı doğru yer çekimi kuvveti ile deformasyon ve stres analizi yapılmıștır. SEA sonuçlarında da deneysel analiz sonuçları ile paralel bir șekilde mesnetler arası mesafe azaldıkça deformasyon miktarında azalma görülmüştür. Oluşan deformasyon sonuçları deneysel sonuçlar ile oldukça yakındır ve kabul edilebilir farklılıktadır. Bu sonuçlar SEM'de ürün deformasyon analizi için güven olușturmaktadır. Deformasyon sırasında olușan gerilimler en fazla mesnet desteğinin bittiği çizgide ve en fazla deformasyon oluşan bölgede oluşmuştur. $\mathrm{Bu}$ sonuçlar kalıp tasarımının SEM ile yapılması için güven oluşturmuştur.

Son olarak SEA ile Eczacıbaşı Yapı Gereçleri AȘ'de üretilen iki farklı boyutta ürün için deformasyon ve stres analizi çalışılmıştır. Görünüşleri aynı iki faklı boyuttaki ürünler SEM'de modellenmiş ve yer çekimi kuvveti yukarı doğru verilmiștir. Bu sayede nihai ürün boyutlarında modellenen ürünler analiz edildiğinde ters deformasyon olușturulmuș ve elde edilen deformasyon miktarı istenilen ürün boyutlarına eklenerek teorik kalıp boyutlarına gidilmiștir. Çubuk analizlerinde olduğu gibi ürün yan bantlarını mesnet olarak düşünülürse deformasyon en çok ön bantta olmuştur. Yine çubuk analizlerinde olduğu gibi ürün boyutu arttıkça deformasyonda artış görülmüştür.

SEA ile çalışması yapılan iki farklı boyutta ürün için ön görülen kalıp tasarım boyutları, gerçek kalıp tasarımlarına göre daha doğru sonuçlar vermiştir. Bu sonuçlar sonlu elemanlar ile ürün tasarımın gerçekte uygulanabilirliğinin olduğunu göstermektedir. Sonraki çalışmalarda vitrifiye çamur analizleri, klozet, bide gibi ürün çeșitlerinde de çalıșmalar yapılarak ürün devreye alma çalışmaları minimize edilebilir.

\section{Kaynakça}

[1] Richerson, D.W., 1982. Modern Ceramic Engineering: Properties, Processing,and Use In Design, 3rd edition, Marcel Dekker, New York, 728s.

[2] Frischholz, P., 2003. Breviary Technical Ceramics, Fahner, Hans Verlag, Selb, Germany, 283s.

[3] Fortuna, D., 2000. Sanitaryware, Faenza (Gruppo Editoriale), Faenza, 188s.

[4] Singer, F. ve Singer, S.S., 1963. Industrial Ceramics, Chapman and Hall, London, U.K, 1457s.

[5] Kivitz, E., Palm, B., Heinrich, J.G., Blumm, J., Kolb, G., 2009 , "Reduction of the porcelain firing temperature by preparation of the raw materials", Journal of European Ceramic Society, 29, 2691-2696. DOI: 10.1016/j.jeurceramsoc.2009.03.029

[6] Özel, E., Tunçel, D.Y., Kara, M.K., 2011, Sert Hammadde Tane Boyutunun Sağlık Gereçleri Porseleninin Fiziksel Özelliklerine Etkisi , Gazi Üniv. Müh. Mim. Fak. Der Cilt 26, No 2, 299-306, 2011. DOI: 10.17341/gummfd.16931

[7] Exner, H. E., 1979. Principles of Single-Phase Sintering, in Reviews on Powder Metallurgy and Physical Ceramics 1, 1-251. Freund Pub. House, TelAviv, Israel.

[8] Rahaman, M.N., 2003, Ceramic processing and sintering, 2nd edition, CRC Press, Boca Raton, Florida, $875 s$.

[9] Porte, F., Brydson, R., Rand, R., Riley, R., 2004, “Creep viscosity of vitreous china", Journal of American Ceramic Society, 87-5, 923-928. DOI: 10.1111/j.1551-2916.2004.00923x

[10] Stathis, G., Ekonomakou, A., Stournaras, C.J., Ftikos, C., 2004, "Effect of firing conditions, filler grain size and quartz content on bending strength and physical properties of sanitaryware porcelain, Journal of European Ceramic Society, 24, 2357-2366. DOI: 10.1016/j.jeurceramsoc.2003.07.003

[11] Uzun, Ö.C., 2006. Pyroplastik deformasyona dirençli sert porselen bünyeler geliştirilmesi ve karakterizasyonu, Gebze İleri Teknoloji Enstitüsü, Mühendislik ve Fen Bilimleri Enstitüsü, Yüksek Lisans Tezi, 89s, Kocaeli.

[12] Bene, P., Bardaro, D., Bello, D., Manni, O, 2010. Numerical modeling and experimental characterization of the pyroplasticity in ceramic materials during sintering, Advances in Science and 
DEÜ FMD 23(67), 285-293, 2021

Technology, 62, 203-208. DOI:

10.4028/www.scientific.net/AST.62.203

[13] De Miranda, S., Patruno, L., Ricci, M., Saponelli, R, Ubertini, F, 2015. Ceramic sanitary wares: Prediction of the deformed shape after theproduction process, Journal of Materials Processing Technology, 215, 309-319. DOI: 10.1016/j.jmatprotec.2014.07.025

[14] Mohanram, A., Lee S.H., Messing, G.L, Green, D.J, 2005. A novel use of constrained sintering to determine the viscous Poisson's ratio of densifying materials, Acta Materialia 53, 2413-2418. DOI: 10.1016/j.actamat.2005.02.003

[15] Moaveni, S. (Çeviren: Ali O. Ayhan), 1999. Sonlu Elemanlar Analizi: Teori ve ANSYS ile Uygulamalar, Palme Yayıncllı, Ankara.

[16] Gupta, K, 2020. Surface Engineering of Modern Materials, Springer-Verlag. ISBN: 9783030432324. 